\title{
Temporal vs discriminative factors in the maintenance of conditioned suppression: A test of the information hypothesis'
}

CYNTHIA SCHEUER, Florida Atlantic University, Boca Raton, Fla. 33432 and WILLIAM H. KEETER, University of Florida, Gainesville, Fla. 32901

The Egger-Miller information hypothesis was tested in the CER situation using a nonovertapping compound conditioning procedure. Six rats were given both delayed and compound conditioning trials consisting of identical CS-US intervals. The findings provided no support for the hypothesis, and further indicated that temporal facturs contributed unly partially to attenuated suppression in SI.

The Eiger and Miller information hypothesis (Egger \& Miller, 1962) states that, in a situation in which there is more than one stimulus predicting primary reinforcement, the more informative stimulus, i.e., the first stimulus to occur, should be the more affective secondary reinforcer. It further stutes that an informationally redundant predictor of primary reinforcement should not acquire secondary reinforcing properties. The hypothesis was confirmed for secondary positive reinforcers in instrumental appetitive situations (Egger \& Miller, 1962, 1963: McCausland, Menzer, Dempsey, \& Birkimer, 1967).

When the hypothesis was applied to situations involving aversive stimulation, it was only partially confirmed. Seligman (1966) tested the Egger-Miller notion in a punishment situation and found that the more informative stimulus acquired greater ability 10 suppress operant behavior than the redundant predictor of shock. The secondoccurring stimulus, however, did acquire suppressive effects above a nonassociative control stimulus. The author suggested that temporal contiguity with shock may have exerted greater control over behavior than did the informational qualities of the stimulus. In another study, Ayres (1967) tested the relevance of the information hypothesis to the conditioned suppression situation by using a partially overlapping compound conditioned stimulus, i.e., SI overlapping S2. He showed that both redundant and unreliable stimuli produced as much suppression as their more informative counterparts. Even after decreasing the interstimulus intervals and lowering the shock intensity, SI and S2 did not differ in their suppressive effects.

The present study attempted (o) recvaluate the relevance of the information hypothesis to the conditioned suppression (CER) situation (Estes \& Skinner, 1941) through the use of a nonoverlapping compound conditioning procedure. If the Egger-Miller hypothesis is applicable to the CER situation, the first stimulus to occur (S1) should be more informative than a redundant predictor of shock (S2), and should subsequently acquire greater negatively reinforcing properties. In the CER situation, these properties of a stimulus are normally measured by the extent to which their presence serves to suppress the operant behavior. The present study further attempted to directly assess the relative contribution of temporal factors in the maintenance of the CER. Although Ayres shortened the interstimulus intervals in order to minimize any differential effects of CS-US interval, no direct test was made to determine the magnitude of the contribu tion of each stimulus interval to behavioral suppression.

\section{SUBJECTS}

Six male albino rats of the SpragueDawley strain served as experimental Ss. The animals were approximately 90-120 day s of age at the start of preliminary training. APPARATUS

All Ss werc trained and tested in a standard lehigh Valley (LVE) operant conditioning chamber (Model No. 1316c) mounted inside a sound at tenuating shell. The manipulandum consisted of an LVE rat lever with an operating pressure of $14 \mathrm{~g}$. Pusitive reinforcement. in the form of $06 \mathrm{cc}$ water, was supplied in the chamber by a solenoid-operated water dipper. Shock was provided by an LVE constant current shock generator (Model No. 1351) and auxiliary scrambler (Model No. 1311 ss), and was calibrated across the grid bars by a Westinghouse dc milliammeter. Dial settings on the shock source were adjusted so as to provide $.50 \mathrm{~mA}$ to the animal at each presentation. Two of the conditioning stimuli were supplied by a Foringer multiple stimulus panel (Model No. 1166-4) and consisted of an intermittent clicking noise $(6 \mathrm{cps} .81 \mathrm{~dB})$ and steady tone $(42 \mathrm{cps}$, $81 \mathrm{~dB}$ ). Illumination from two $7 . W$ cue lights served as the third stimulus event. All other contingencies were programmed automatically by electromagnetic switching and timing circuits, and responses were recorded on electromagnetic counters and a Gerbrand cumulative recorder. Control equipment was in a room adjoining the experimental room, and white noise was supplied in the test room in order to mask extraneous auditory stimuli.

\section{PROCEDURE}

During the week prior to preliminary lever press training, Ss were allowed access to water for $15 \mathrm{~min}$ a day. After the beginning of training, each $S$ was permittid water only during the 15 min immediately following the experimental session, and was maintained on a diet of Purina Lab Chow except during 1 h sessions in the operant chamber. Each $S$ was begun on a CRF schedule and the response ricquilement $u$ as gradually increased to VI I min. When VI rates had stahilized (less than 10' change for three consecutive sessions), habituation trials were initiated.

During habituation sessions. each $\mathrm{S}$ was given six $6(-$-sec presentations wi we of the three stimuli on a given dil. Habituation trials were continued until idil $S$ 's daily "suppression ratio" in the presence of each stimulus exceeded .45. The suppression ratio was of the form $C S / P R E$ and $C S$ (Annau \& Kamin, 1961). and contrasts the frequency of responding during the CS with a comparable interval of time immediately preceding CS onset. The ratio has limits of .00 and 1.00 with .00 representing complete suppression, .50 representing no effect of the $C S$, and 1.00 representing the case in which no responses occur prior to CS onset but some do occur during the CS.

Following habituation to each CS, the CER procedure was superimposed on the

Table I

Specific Stimulus Conditions for Each of the Six Experimental Ss

\begin{tabular}{|c|c|c|c|}
\hline Subject & $\begin{array}{c}\text { SI used in the } \\
\text { compound } \\
\text { paradigm }\end{array}$ & $\begin{array}{l}\text { S? used in the } \\
\text { compound } \\
\text { paradigm }\end{array}$ & $\begin{array}{c}\text { S3 used in the } \\
\text { delayed } \\
\text { paradigm }\end{array}$ \\
\hline 1 & tons & click & light \\
\hline 2 & click & tons & light \\
\hline 3 & light & click & tone \\
\hline 4 & ilick & light & tons \\
\hline 5 & tons & lighlut & ilick \\
\hline 6 & light & (t)inc & Alisk \\
\hline
\end{tabular}




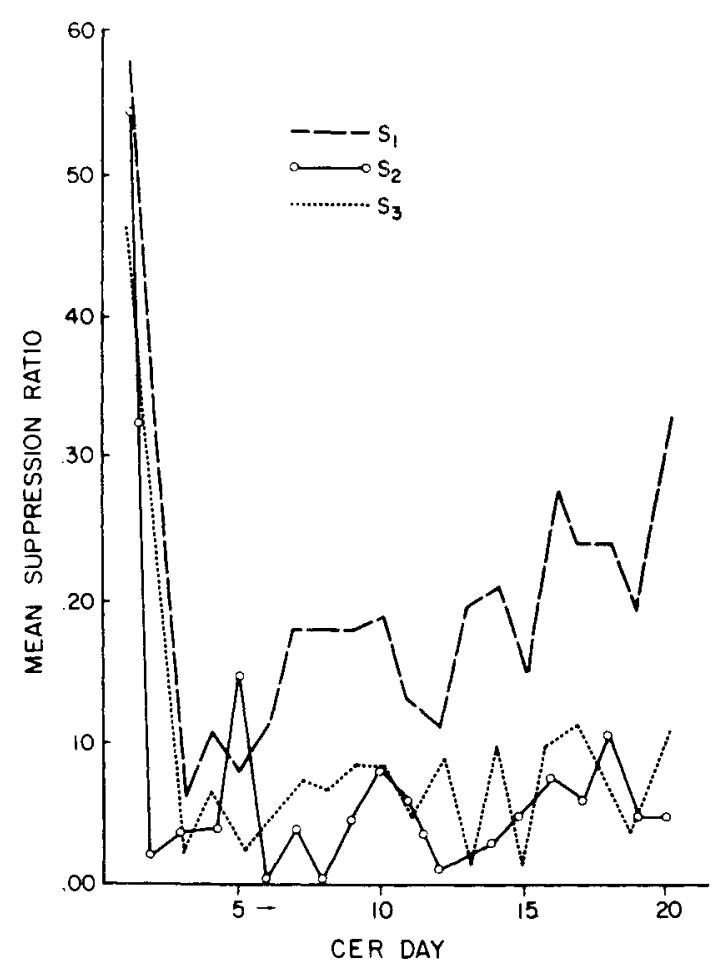

Fig. 1. Mean suppression ratios during S1, S2, and the first $30 \mathrm{sec}$ of $S 3$ across the 20 CER training days.

appetitively reinforced VI baseline. Each session consisted of three delayed conditioning trials and three nonoverlapping compound trials in an alternating fashion with the first daily trial being a delayed trial. A compound trial consisted of the presentation of $30 \mathrm{sec}$ of S1 which terminated with the onset of the $30 \mathrm{sec}$ of $\mathrm{S} 2$. The termination of $\mathrm{S} 2$ was contiguous with a brief electric shock $(.50 \mathrm{~mA}, .50 \mathrm{sec})$. A delayed trial consisted of $60 \mathrm{sec}$ of a third stimulus whose offset was simultaneous with shock occurrence. The relevant stimuli were interchanged for each of the six Ss so as to achieve complete counterbalancing. The six conditions are represented in Table 1. Delayed trials were intended to serve as a baseline from which any loss of suppression due to the use of a constant CS-US interval could be determined. The informational properties affecting the frequency of responding in each segment of the compound were directly compared to the behavior generated during a comparable period of time during delayed trials.

The CER procedure was in effect for 20 consecutive daily sessions.

\section{RESULTS}

Figure 1 contrasts the mean amount of suppression occurring during each segment of the compound and the first $30 \mathrm{sec}$ of S3 for the 20 CER training days for the six Ss combined. Acquisition rates in S1 and S2 were comparable, but, beginning with Session 6, suppression began to markedly attenuate during S1. A Wilcoxon matchedpairs signed-ranks test between $S 1$ and S2 ratios showed significance across the 20 training days $(T=4, p<.005$, one-tailed test). This attenuation of suppression during $\mathrm{S} 1$ was evident in each of the six Ss, although the training day on which the curves began to diverge varied across animals. The smallest amount of attenuation occurred for Ss 2 and 4 , both of which were given the clicker as S1. No other differential effects were observed relating to specific stimulus conditions.

An analysis conducted between the mean suppression ratios obtained for $\mathrm{S} 1$ and the ratios observed during the first $30 \mathrm{sec}$ of S3 were also highly significant $(T=0, p<.005$, one-tailed test), indicating that the attenuation observed during $\mathrm{S} 1$ of the compound was not attributable solely to its temporal relationship to shock onset since CS-US intervals were identical for both conditions. In order to determine whether CS-US interval had any substantial effect on suppression, a similar analysis was conducted between the ratios obtained during each 30-sec segment of the delayed str.nulus. The findings showed a significant effect due to CS-US interval ( $T=7, p<.005$, onetailed test). However, the attenuation observed in $\mathrm{Sl}$ of the compound was considerably greater than that which would be expected merely on the basis of a temporal discrimination.

\section{DISCUSSION}

The results of the present study provided no support of the Egger-Miller information hypothesis as relevant to the CER situation. The redundant predictor of shock, S2, served to suppress the ongoing operant significantly more than its more informative counterpart, S1. Furthermore, the extent to which each stimulus component in the compound depressed lever pressing could not be attributed solely to its temporal relationship to US onset. Although the CS.US interval did contribute substantially to the differential suppression ratios occurring in each component of the compound, the marked attenuation that occurred during $\mathrm{S} 1$ was substantially greater than that which occurred during an identical interval on delayed trials.

One possible explanation of the lack of support for the Egger-Miller notion may concern one of its basic assumptions, at least regarding its applicability to the CER situation. The hypothesis assumes that the informational properties of a stimulus determine its secondary reinforcing properties. In the CER situation, the conditioned aversive properties of a stimulus are measured by the amount of suppression which occurs in its presence. Each stimulus component, however, may be providing different information to the subject. S2 appears to serve as a cue for "shock about to come," whereas S1, although highly informative, seems, in contrast, to serve as a cue for a safe period, i.e., "shock not about to come." If this were the case, then S1 should begin to facilitate responding to baseline levels at a rate beyond that normally to be expected merely on the basis of temporal cues. The present data confirmed such a prediction.

Further attempts are being made to investigate the possibility that the onset and offset of S1 have different informational properties. That is, it seems possible that the onset of S1 serves as a safety signal and its termination serves as a cue for the occurrence of shock. A basic test of such a possibility would require the presentation of S2 alone following compound training to an $\mathrm{S} 1-\mathrm{S} 2$ sequence. If suppression is markedly attenuated in S2, this latter interpretation would appear highly tenable.

REFERENCES

ANNAU, $Z$, \& KAMIN, L. J. The conditioned emotional response as a function of in tensity of the US. Joumal of Comparative \& Phy siological Psychology, 1961, 54, 428-432.

AYRES, J. J. Conditioned suppression and the information hypothesis. Journal of Comparative \& Physiological Psychology, 1966, 62. 21-25.

Psychon. Sci., 1969, Vol. 15 (1) 
EGGER, M. D., \& MILLER, N. E. Secondary reinforcement in rats as a function of information value and reliability of the stimulus. Joumal of Experimental Psy chology, $1962,64,97 \cdot 104$.

EGGER, M. D., MILLER, N. E. When is reward reinforcins? An experimental study of the information hypothesis. Joumal of Comparative \& Physiological Psychology, 1963, 56, 132-137.

ESTES, W. K., \& SKINNER, B. F. Some quantitative properties of anxiety. Joumal of Experimental Psychology, 1941, 29, 390-400.
MCCAUSLAND, D. F., MENZES, G. W., DEMPSEY, T. K., \& BIRKIMER, J. C. Response-contingent and non-contingent informative and redundant secondary reinforcers. Psychonomic Science, 1967, 8, 293-294.

SELIGMAN, M. E. P. CS redundancy and secondary punishment. Joumal of Experimental Psychology, 1966, 72, 546-5s0.

\section{NOTE}

1. This research was partially supported by NSF Grant No. 616-015 to the University of Florida.

\section{Olfactory cues and spontaneous alternation behavior'}

\author{
CHARLES L. RICHMAN, Wake Forest \\ University, Winston-Salem, N.C. 27109, \\ PAMELA JUELS, PHILIP PECKINPAUGH, \\ and ROBERT M. STUTZ, University of \\ Cincinnati, Cincinnati, Ohio 45221
}

Experiments were conducted to determine the effect of reward and drive on spontaneous alternation behavior (SAB) across trials. It was suggested that reinforcing severely food-deprived rats reduced $S A B$ across trials when direction was the sole relevant cue, but no reduction was found when odor cues were present. It was shown that $S A B$ decreases as a function of both days and trials of training.

In 1952, Montgomery suggested that spontaneous alternation behavior (SAB) was a result of an exploratory tendency. Using a cross-maze, Montgomery (1952) found that rats performed the same body-turn response in order to enter different goal arms Montgomery (1952) proposed that SAB was a special case of the rat's exploratory tendency, i.e., the novelty and hence the attractiveness of the goal entered on Trial 1 diminishes relative to the goal arm not visited.

Recently Douglas (1966) demonstrated that rats avoid their own odor trail. Since Montgomery (1952) used a procedure that did not control for odor trail, one might hypothesize that the Ss in his experiment were either avoiding their own odor and/or using odor as a discriminative cue for exploration. This study was designed to determine if, indeed, Montgomery's results might better be explained in terms of odor trail.

\section{EXPERIMENT 1 \\ Subjects}

The Ss were 4 experimentally naive hooded rats and 16 albino rats approximately 90 days old.

\section{Apparatus}

A cross-maze was constructed of unpainted white pine. All maze compartments were 2 in. wide and 4 in. high. The start and goal boxes were 8 in. long and the start and goal arms were 14 in. long. A plywood panel was used to block off one of the starting stems, at the choice point, thereby converting the cross into a $T$-maze. A wire mesh top covered the maze. The maze was placed on the floor of an $8 \times 8 \mathrm{ft}$ windowless room, illuminated by a $15-\mathrm{W}$ bulb suspended $3 \mathrm{ft}$ above the choice point. Procedure

Preliminary training consisted of 5 days of gentling followed by 2 days of six reinforced trials per day in a straight-alley maze (4 ft $x \quad 2$ in. $x \quad 4$ in.). During Preliminary Training Days $1-5$, Ss were maintained on a daily ad lib water schedule and 9-g Rockland lab chow. On Preliminary Training Days 6 and 7 and Experimental Days 14 , Ss were food-deprived except for the food consumed during training. Because of the Ss' apparent weakness they were given $4 \mathrm{~g}$ of lab chow, in their home cages, during Experimental Days 5 through 7.

Five Ss were randomly assigned to four groups; each group contained one hooded and four albino rats. The experiment consisted of a 2 by 2 design with two types of trial order and two odor trail conditions. The first letter (S or $\mathrm{C}$ ) refers to the trial starting stem order (successive or counterbalance) and the second ( $\mathrm{P}$ or $\mathrm{A}$ ) refers to the presence or absence of S's own odor trail. Groups S-P and S-A day's run began from one start stem direction [e.g., $(\mathrm{N})]$ for six successive trials then from the opposite start stem direction the next day [e.g., (S)] Groups $C \cdot P$ and $C$-A starting stem was varied within a day's run [e.g., (S), (N), (N), (S), $(\mathrm{S}),(\mathrm{N})]$. Odor trail presence or absence was manipulated in the following manner: Clean heavy brown paper inserts, covering the floor and walls of the goal arms, were used on Trial 1 each day. During each ITI for Group $P$, clean brown paper was inserted in the goal arm not visited so that there was always a "fresh" odor-trail goal arm and "clean" one. The brown paper inserts were changed in both arms at the end of each trial for Group A.

For 7 days each $\mathrm{S}$ was given six trials a day, thereby providing an opportunity for 35 goal-arm and/or odor-trail alternation responses. Animals received about 300-mg lab chow for entering either goal arm. The ITI ranged from 5 to $10 \mathrm{sec}$. A wooden block between the choice point and the goal arms prevented retracing.

Results

SAB was evaluated using a $\chi^{2}$ test comparing the observed distribution of alternation and nonalternation responses with a distribution based upon chance expectancies. $A \chi^{2}$ test was used for each of the four groups, the tests revealed that Groups S-P and C-P demonstrated SAB (79\% and $72 \%$ alternations with $\chi^{2}=19.68$, $\mathrm{df}=1, \mathrm{p}<.01$ and $\chi^{2}=9.94, \mathrm{df}=1$, $\mathrm{p}<.01$, respectively), but Groups $\mathrm{S}-\mathrm{A}$ and C-A did not demonstrate SAB ( $46 \%$ and $44 \%$ alternations with $\chi^{2}=.64, \mathrm{df}=1, \mathrm{p}>.10$ and $\chi^{2}=1.26$, $\mathrm{df}=1, \mathrm{p}>.10$, respectively). A t test comparing the number of goal-arm alternation responses between the successive and counterbalance trial order procedures ( $\mathrm{S}$ and $\mathrm{C}$ ) was statistically nonsignificant $(p>.05)$.

Discussion

Experiment 1 suggested that Montgomery's (1952) SAB finding was probably due to the rats' utilizing their own odor trails. The present study supported Douglas' (1966) demonstration that rats avoid their own odor trail at a higher-thanchance rate. However, Douglas (1966) also found that rats showed SAB to direction, e.g., east (E) and west (W), when no other cues were present. Thus, the control groups (Groups S-A and C-A) in this experiment should have demonstrated an above-chance rate of alternation behavior to the direction cue; these groups were in fact slightly below chance.

\section{EXPERIMENT 2}

In Experiment 1, Ss that were presented with direction as the sole cue failed to demonstrate SAB although Douglas (1966) found that Ss showed $\mathrm{SAB}$ to direction at a rate of about $63.5 \%$. The purpose of 